\title{
Effect of plateau pika disturbance on the ecosystem services of alpine grasslands
}

\author{
Ying Ying Chen ${ }^{1}$, Huan Yang ${ }^{1}$, Gen Sheng Bao ${ }^{2}$, Xiao Pan Pang ${ }^{1}$, and Zheng Gang Guo ${ }^{3}$ \\ ${ }^{1}$ Lanzhou University \\ ${ }^{2}$ Qinghai University \\ ${ }^{3}$ State Key Laboratory of Grassland Agro-ecosystems
}

January 13, 2021

\begin{abstract}
Herbivore disturbance can affect the grassland ecosystem services though creating extensive disturbances vegetation and soil. This study focused on plateau pika (Ochotona curzoniae) disturbance to investigate the effect of disturbance by small burrowing herbivores on ecosystem services of alpine grasslands though five sites. In this study, the palatable plant biomass, plant species richness, soil water storage, soil organic carbon, total nitrogen, phosphorus and potassium stocks were used to estimate the forage availability, biodiversity conservation, water conservation, carbon sequestration and soil nutrient maintenance. This study showed that plateau pika disturbance was related to higher plant species richness and soil organic carbon stock, associated with lower palatable plant biomass and soil water storage, and had no effect on total potassium stock, whereas the responses of soil total nitrogen and phosphorus stocks to plateau pika disturbance were different among sites. The palatable plant biomass, plant species richness, soil organic carbon, total nitrogen and phosphorus stocks showed downward parabolas, whereas the soil water storage showed a decreasing trend with increasing plateau pika disturbance intensity. These results indicated that the role of plateau pikas is dependent not only on the management target of alpine grasslands but also on the plateau pika disturbance intensity.
\end{abstract}

Title: Effect of plateau pika disturbance onthe ecosystem services ofalpine grasslands

Running title: plateau pika alters the alpine grassland ecosystem services

Ying Ying Chen ${ }^{\mathrm{a}}$, Huan Yang ${ }^{\mathrm{a}}$, Gen Sheng Bao ${ }^{\mathrm{b}}$, Xiao Pan Pang ${ }^{\mathrm{a}}$, Zheng Gang Guo ${ }^{\mathrm{a}^{*}}$

${ }^{a}$ Key Laboratory of Grassland Livestock Industry Innovation, Ministry of Agriculture and Rural Affairs; Engineering Research Center of Grassland Industry, Ministry of Education; College of Pastoral Agriculture Science and Technology, Lanzhou University, Lanzhou, 730020, P. R. China

${ }^{b}$ Academy of Animal and Veterinary Sciences, Qinghai University (Qinghai Academy of Animal and Veterinary Sciences), Xining, China

${ }^{*}$ Correspondence, Zheng Gang Guo, E-mail:guozhg@lzu.edu.cn

\section{Acknowledgments}

The authors would like to thank Jing Zhang, Qian Wang, Hai Peng Xu, Wen Na Zhang, Juan Wang, Ding Yang, Jie Li, Fu Yun Qiao, Di Gang Zhi, Hao Hao Qi, Gan Lin Feng and Yuan Yuan Duan from Lanzhou University for the contributions made to this study through their field assistance and laboratory analysis. This study was funded by the Key Laboratory of Superior Forage Germplasm in the Qinghai-Tibetan Plateau (2020-ZJ-Y03), the Changjiang Scholars and Innovative Research Team in University (IRT17R50), the Major 
Project of Xizang autonomous region (XZ201901NA03) and the National Natural Science Foundation of China (31172258), and the 111 Project (B12002).

\title{
Conflict of Interest Statement
}

The authors declare that they have no known competing financial interests or personal relationships that could have appeared to influence the work reported in this paper.

\section{Author contributions}

Ying Ying Chen and Zheng Gang Guo conceived the ideas and designed the methodology; Ying Ying Chen, Xiao Pan Pang, Gen Sheng Bao and Huan Yang collected the data; Ying Ying Chen analysed the data; Ying Ying Chen and Zheng Gang Guo led the writing of the manuscript. All of the authors contributed critically to the drafts and gave their final approval for publication.

\begin{abstract}
Herbivore disturbance can affect the grassland ecosystem services though creating extensive disturbances vegetation and soil. This study focused on plateau pika (Ochotona curzoniae) disturbance to investigate the effect of disturbance by small burrowing herbivores on ecosystem services of alpine grasslands though five sites. In this study, the palatable plant biomass, plant species richness, soil water storage, soil organic carbon, total nitrogen, phosphorus and potassium stocks were used to estimate the forage availability, biodiversity conservation, water conservation, carbon sequestration and soil nutrient maintenance. This study showed that plateau pika disturbance was related to higher plant species richness and soil organic carbon stock, associated with lower palatable plant biomass and soil water storage, and had no effect on total potassium stock, whereas the responses of soil total nitrogen and phosphorus stocks to plateau pika disturbance were different among sites. The palatable plant biomass, plant species richness, soil organic carbon, total nitrogen and phosphorus stocks showed downward parabolas, whereas the soil water storage showed a decreasing trend with increasing plateau pika disturbance intensity. These results indicated that the role of plateau pikas is dependent not only on the management target of alpine grasslands but also on the plateau pika disturbance intensity.
\end{abstract}

\section{KEYWORDS}

Forage availability; Biodiversity conservation; Water conservation; Carbon sequestration; Soil nutrient maintenance

\section{INTRODUCTION}

Grassland covers approximately $40 \%$ of the Earth's land surface (Pang et al., 2020b), and its multiple ecosystem services can sustain animal production, ecological functions, flora and fauna, and other human welfare (Costanza et al., 1997; Dong et al., 2020; Zhang et al., 2018). However, grassland ecosystem services have been demonstrated to be affected by herbivore disturbance (Lu et al., 2017; Martínez-Estévez et al., 2013).

Herbivore disturbance often has impacts on grassland ecosystem services (Lu et al., 2017) by altering the plant community (Lu et al., 2017; Niu et al., 2010; Wu et al., 2009) and soil properties (Lu et al., 2017; Sun et al., 2011; Wang et al., 2012a). Large herbivore grazing has been verified to influence grassland ecosystem services (Lu et al., 2017; McGranahan et al., 2012; Niu et al., 2010; Sun et al., 2011; Woldu and Saleem, 2000). In addition to large herbivores, tens of thousands of small burrowing herbivores usually create extensive disturbances on grassland vegetation and soil (Davidson et al., 2012; Pang et al., 2020a) by developing burrow systems (Sun et al., 2015), excreting feces and urine (Zhang et al., 2016), consuming plants (Liu et al., 2017; Sun et al., 2015), clipping tall plants (Zhang et al., 2020), and producing bare soil patches (Guo et al., 2012a, 2012b; Yu et al., 2017a, 2017b). Currently, a few studies have used data from one site to examine the effect of prairie dog disturbance on grassland ecosystem services in arid regions (Martínez-Estévez et al., 2013). However, the effect of disturbance by small burrowing herbivores on vegetation and soil varies with topography and microclimate (Pang et al., 2020a, 2020b; Wang et al., 2020a; Yu et al., 2017a). Therefore, it 
is necessary to use data from multiple sites to identify a general pattern concerning the effect of disturbance by small burrowing herbivores on grassland ecosystem services, which can provide information for grassland management.

Plateau pikas (Ochotona curzoniae) are a common, small burrowing herbivore in alpine grasslands of the Qinghai-Tibetan Plateau (Smith \& Foggin, 1999; Zhang et al., 2020). This small animal is considered a pest in China (Liu et al., 2013; Pang \& Guo, 2017) since it often exacerbates alpine grassland degradation (Liu et al., 2013; Wilson \& Smith, 2015; Zhang et al., 2016), and it has been widely eradicated by poison (Wilson \& Smith, 2015). However, some studies argue that plateau pikas are key animals in alpine grassland ecosystems (Smith \& Foggin, 1999; Smith et al., 2019). This kind of disagreement has encouraged professionals to reevaluate the role of plateau pikas in alpine grassland ecosystems. Thus, plateau pika disturbance in relation to alpine grassland ecosystem services is possibly a better way to gain insight into the roles of plateau pikas in alpine grassland ecosystems. In theory, alpine grasslands encompass a variety of ecosystem services, as well as grasslands in Europe (Jäger et al., 2020; Obermeier et al., 2019) and North America (Martínez-Estévez et al., 2013), whereas the main ecosystem services of alpine grasslands in the Qinghai-Tibetan Plateau are often given attention for forage availability, biodiversity conservation (Dong et al., 2010), water conservation (Dong et al., 2020; Wen et al., 2013), carbon sequestration (Dong et al., 2020; Zhang et al., 2015) and soil nutrient maintenance (Wen et al., 2013). However, whether plateau pika disturbance influences alpine grassland ecosystem services has not yet been well documented.

This study employs plateau pikas as a study animal to investigate the effect of disturbance by small burrowing herbivores on forage availability, biodiversity conservation, water conservation, carbon sequestration and soil nutrient maintenance services across five sites. Specifically, this study hypothesizes that (1) plateau pika disturbance is related to lower forage availability services and higher biodiversity conservation services; (2) plateau pika disturbance is associated with higher water conservation services; (3) plateau pika disturbance correlates with higher carbon sequestration services; and (4) plateau pika disturbance is related to lower soil nutrient maintenance services.

\section{MATERIALS AND METHODS}

\subsection{Study sites}

Plateau pikas can live in various habitats with different soil types, topographies, and microclimates. To identify a general pattern of how plateau pika disturbance influences the ecosystem services of alpine grasslands, this study selected five sites with different alpine grassland types, topographies and microclimates as field survey areas. These five survey sites have a similar typical plateau continental climate, with mean annual temperatures of 3.3 in Luqu (102deg $\left.10^{\prime}-102^{\circ} 52^{\prime} \mathrm{E}, 34^{\circ} 16^{\prime}-34^{\circ} 37^{\prime} \mathrm{N}\right), 2.0$ in Gangcha $\left(99^{\circ} 53^{\prime}-100^{\circ} 36^{\prime} \mathrm{E}, 37^{\circ} 17^{\prime}-\right.$ $\left.37^{\circ} 29^{\prime} \mathrm{N}\right), 2.0$ in Haiyan $\left(100^{\circ} 37^{\prime}-100^{\circ} 58^{\prime} \mathrm{E}, 36^{\circ} 51^{\prime}-37^{\circ} 14^{\prime} \mathrm{N}\right)$, 2.1 in Qilian $\left(99^{\circ} 28^{\prime}-100^{\circ} 54^{\prime} \mathrm{E}, 37^{\circ} 58^{\prime}-38^{\circ} 27^{\prime} \mathrm{N}\right)$, and 3.7 in Gonghe $\left(99^{\circ} 41^{\prime}-100^{\circ} 12^{\prime} \mathrm{E}, 36^{\circ} 21^{\prime}-36^{\circ} 36^{\prime} \mathrm{N}\right)$. These survey areas range in elevation from $3000 \mathrm{~m}$ at the Gangcha survey site to $3550 \mathrm{~m}$ at the Luqu survey site, with average annual precipitation varying from 350 $\mathrm{mm}$ at the Gonghe survey site to $630 \mathrm{~mm}$ at the Luqu survey site. According to the Chinese soil classification system (Gong, 2001), the soil type is alpine meadow soil in the five survey sites, similar to Cambisol in the WRB soil classification system. Soil nutrients are different among the five survey site areas (Pang et al., 2020a, 2020b).

The five field survey areas were placed in cold-season areas, which were fenced from mid-April to September, and fences were opened to grazing yaks with a 3.4 yaks ha-1 grazing stock rate from mid-October to early April (Zhang et al., 2020). The alpine grasslands in the five survey areas were dominated by Kobresia humilis andKobresia pygmaea. Plateau pikas were the only small burrowing herbivores in the field survey areas, and their population generally peaked in August (Pang et al., 2020a, 2020b; Qu et al., 2013), implying that sampling plants and soil in August may best reflect the effect of plateau pika disturbance on alpine grassland ecosystem services.

\subsection{Evaluating ecosystem services of alpine grassland}


Plateau pika disturbance often produces many bare soil patches nested in alpine grasslands (Wilson \& Smith, 2015; Yu et al., 2017b; Zhao et al., 2019). The plot scale was suggested to better reflect the effects of plateau pika disturbance on plant biomass and soil properties (Pang et al., 2020a, 2020b) because it can simultaneously consider the heterogeneity of soil properties in the presence of plateau pikas and the difference in plant biomass and soil properties between areas with and without plateau pikas (Pang et al., 2020b). Therefore, this study used a plot scale to examine plateau pika disturbance and its disturbance intensity in relation to forage availability, water conservation, carbon sequestration and soil nutrient maintenance services and used a quadrat scale to examine plateau pika disturbance and its disturbance intensity in relation to the biodiversity conservation service. Although there were many kinds of bare soil patches in the alpine grasslands, this study was restricted to the bare soil patches induced by plateau pikas. In the presence of plateau pikas, the soil water storage, soil organic carbon, soil total nitrogen, phosphorus and potassium stocks were calculated in the bare soil surface and vegetated surface, respectively.

In this study, the forage availability service was estimated by palatable plant biomass (Martínez-Estévez et al., 2013). The biodiversity conservation service was estimated by plant species richness (Wen et al., 2013). Water conservation services can be assessed by soil water storage (Ouyang et al., 2011). The carbon sequestration service can be evaluated by the soil organic carbon stock (Wen et al., 2013). Soil nutrient maintenance services can be assessed by soil total nitrogen, phosphorus, and potassium stocks (Wen et al, 2013).

\subsection{Survey design}

Plateau pikas are social animals that usually live in low and open habitats, and their young offspring often stay with the family in their birth year since they are philopatric (Wang et al., 2020; Yu et al., 2017b). Therefore, plateau pikas are territorial and patchy in a vast alpine grassland. Because the diffusion of plateau pikas is a gradual process (Pang et al., 2020b), it is easy to find sites without plateau pika disturbance, even though these sites might be potentially suitable habitats for plateau pikas.

A stratified random and paired design was used to select the plots. At each of the five sites, this study first selected 10 disturbed plots where plateau pikas were present or active burrow entrances were observed. These disturbed plots were 3 to $5 \mathrm{~km}$ from each other. Second, a paired adjacent undisturbed plot without the presence of plateau pikas and active burrow entrances was selected for each disturbed plot. The distance between each disturbed plot and its paired undisturbed plot ranged from 500 to $1000 \mathrm{~m}$. If the distance between each disturbed plot and its paired undisturbed plot was too close, plateau pikas could possibly move from the disturbed plot to the undisturbed plot. To ensure that each disturbed plot had a paired undisturbed plot to the greatest extent, each paired plot was ensured to share the same alpine grassland, with no obvious differences in soil types, topography or microclimate. In total, there were 10 pairs of plots at each site and 100 plots across five sites, including 50 disturbed plots and 50 undisturbed plots. The size of each plot was $35 \mathrm{~m} \times 35 \mathrm{~m}$, similar to the average area of plateau pika's home range of $1262.5 \mathrm{~m}^{2}$ (Fan et al., 1999). Owing to grazing from mid-October to early April, the litter in each plot was consumed by livestock, which was better for estimating the aboveground biomass during the warm season.

\subsection{Field sampling}

Field surveys were conducted in early August 2020. First, the active burrow entrance at each plot was estimated by the "plugging tunnels method", in which the burrows were plugged for 3 days, and the number of plugs that were cleared by the plateau pikas to allow access to the meadow surface were recorded (Guo et al., 2012a; Yu et al., 2017b). The average number of burrow entrances with cleared plugs in 3 days was considered the density of active burrow entrances per plot; second, the area of each bare soil patch in the disturbed plot was measured by the segmentation method (Han et al., 2011), and then the sum of all bare soil patches areas in each disturbed plot was calculated as the bare soil area for that disturbed plot; third, five vegetated quadrats $(1 \mathrm{~m} \times 1 \mathrm{~m})$ were placed on the vegetated surface approximately $8 \mathrm{~m}$ apart along a $\mathrm{W}$ pattern in all plots (disturbed and undisturbed plots), and they were moved slightly to avoid bare soil patches in disturbed plots if needed; fourth, a bare soil patch was selected as a paired bare soil quadrat 
for each vegetated quadrat in the disturbed plot, and the distance between each paired bare soil quadrat and vegetated quadrat was as short as possible, less than approximately $1 \mathrm{~m}$. Thus, there were five paired quadrats, consisting of five vegetated quadrats and five bare soil quadrats in each disturbed plot, and there were five vegetated quadrats in each undisturbed plot since this study only focused on bare soil patches induced by plateau pikas.

In each vegetated quadrat of the disturbed or undisturbed plot, all vascular plant species were identified, and their number was recorded as the plant species richness of a community. Then, all plants rooted in a quadrat were harvested into palatable and unpalatable plants (Pang \& Guo, 2017). Finally, all palatable plant samples were placed into envelopes and carried back to the laboratory.

Generally, most burrows derived from plateau pika activities were less than $20 \mathrm{~cm}$ depth (Yu et al., 2017b), although a few burrows extended to depths of $60 \mathrm{~cm}$ (Fan et al., 1999). In addition, the majority of the plant roots in the alpine grasslands of the Qinghai-Tibetan Plateau are in the top $20 \mathrm{~cm}$ of the soil. Therefore, this study collected soil samples at a depth of $20 \mathrm{~cm}$. The soil samples were collected from vegetated quadrats and bare soil quadrats for each disturbed plot, whereas they were collected from vegetated quadrats for each undisturbed plot. Before collecting the soil samples, plants and litter were cleared from the soil surface. First, a 5-cm diameter soil auger was used to collect soil samples, with which soil organic carbon and soil nutrient concentrations (total nitrogen, phosphorus and potassium) were measured; second, soil profiles in each quadrat were produced by a spade, and a stainless-steel cutting ring (the volume was $100 \mathrm{~cm}^{3}$ ) was used to collect soil cores to determine soil bulk density and soil water content. The soil samples for measuring soil bulk density were quickly packed into aluminum boxes with recorded weight, and each aluminum box was numbered. The aluminum boxes with fresh soil were weighed and recorded on the spot, and these aluminum boxes with soil samples were stored at $4^{\circ} \mathrm{C}$ and transported to the laboratory.

\subsection{Analysis of samples}

In the laboratory, palatable plant samples were dried in an oven at $80^{\circ} \mathrm{C}$ for $48 \mathrm{~h}$ and weighed. The soil samples used for measuring soil bulk density and soil water content were dried to a constant weight at $105 \pm 2$, and the aluminum boxes with dry soil were weighed and recorded. The soil samples used for measuring organic carbon, total nitrogen, total phosphorus and total potassium concentrations were air-dried and passed through a 2-mm sieve to remove gravel and roots. The soil organic carbon and total nitrogen concentrations were measured by the $\mathrm{K}_{2} \mathrm{Cr}_{2} \mathrm{O}_{7}-\mathrm{H}_{2} \mathrm{SO}_{4}$ oxidation method of Walkey and Black (Naelson and Sommers, 1982) and the Kjeldahl procedure (Foss Kieltec 8400, FOSS, DK). The soil total phosphorus and total potassium concentrations were measured by Mo-Sb colorimetry (UV-2102C, UNICO, Shanghai, China, and flame photometry, Model 2655-00 Digital Flame Analyzer, Cole-Parmer Instrument Company, Chicago, IL, USA) after the soil was digested with perchloric and nitric acid (Nelson and Sommers, 1982).

The soil bulk density and soil organic carbon and nutrient concentrations (total nitrogen, phosphorus and potassium) were used to calculate the soil organic carbon, total nitrogen, phosphorus and potassium stocks (Pang et al. 2020a, 2020b). The soil bulk density and soil water content were used to calculate the soil water storage (Jia et al., 2020). The soil water content was estimated bySWC $\left.=\frac{(\mathrm{WsDs})}{(\mathrm{WsAm}}\right) \times 100 \%$, where $S W C$ is the soil water content (\%); Ws and Dsare the weight of the aluminum box with a fresh soil sample (g) and the weight of the aluminum box with a dry soil sample (g), and $A m$ is the weight of the aluminum box (g).

\subsection{Calculations}

The bare soil area consisted of all bare soil patches, and the vegetated surface area was estimated by the plot areas minus the bare soil areas. The bare soil area in the disturbed plot was estimated by adding all bare soil patch areas. In each undisturbed plot, bare soil areas were considered zero, and the vegetated surface area was considered $100 \%$.

The palatable plant biomass was calculated by the following equation: $G B=B_{q} ? \delta_{a}$, where $G B, B_{q}$ and $\delta_{a}$ were the palatable plant biomass at the plot, palatable plant biomass at the quadrat scale $\left(\mathrm{g} \mathrm{m}^{-2}\right)$ and vegetated surface area, respectively. The plant species richness in a quadrat $(1 \mathrm{~m} \times 1 \mathrm{~m})$ was measured by the 
species number of each quadrat. Soil water storage was performed using the method recommended by Jia et al. (2020). The soil organic carbon stock per plot was estimated by using the methods described by Pang et al. (2020a). The soil total nitrogen, phosphorus and potassium stocks per plot were quantified according to the method of Pang et al. (2020b).

\subsection{Data analysis}

To develop a general pattern of ecosystem services in relation to plateau pika disturbance across the five sites, two-way analysis of variance (ANOVA) with a general linear model (GLM) was used to analyze the effects of plateau pika disturbance, the sites and their interactions on palatable plant biomass, plant species richness, soil water storage, soil organic carbon, soil total nitrogen, soil total phosphorus and soil total potassium stocks. In the model, the abovementioned parameters acted as response variables, and plateau pika disturbance, site and their interactions were introduced as fixed effects.

In addition, the paired-samples $\mathrm{T}$ test was used to examine the differences in palatable plant biomass, plant species richness, soil water storage, soil organic carbon stock, soil total nitrogen stock, soil total phosphorus stock and soil total potassium stock between the disturbed and undisturbed plots at each site. Here, the "disturbed plots" and "undisturbed plots" were regarded as one-to-one corresponding samples, the paired plots were considered random factors, and the disturbed/undisturbed plots were considered to be fixed effects, which were used to verify the results from five sites and to support the general pattern.

To clarify the responses of palatable plant biomass, plant species richness, soil water storage, soil organic carbon stock, soil total nitrogen stock, soil total phosphorus stock and soil total potassium stock to the plateau pikas disturbance intensity, a linear model (LM) was used to examine the relationships between palatable plant biomass, plant species richness, soil water storage, soil organic carbon stock, soil total nitrogen stock, soil total phosphorus stock and soil total potassium stock and active burrow entrance densities in all disturbed plots and in an individual site. The active burrow entrance densities were considered to be a fixed factor, and they were used to construct regression curves between palatable plant biomass, plant species richness, soil water storage, soil organic carbon stock, soil total nitrogen stock, soil total phosphorus stock and soil total potassium stock and active burrow entrance densities.

Significant differences were assessed at $P<0.05$. All statistical analyses were performed with the SPSS 17.0 software package from SPSS Inc., Chicago, IL, USA.

\section{RESULTS}

\subsection{Effects of plateau pika disturbance on the ecosystem services of alpine grasslands}

\subsubsection{Effect of plateau pika disturbance on palatable plant biomass}

Plateau pika disturbance (disturbance) significantly affected the palatable plant biomass (Table 1), whereas the five sites (site) did not affect the palatable plant biomass. The interactions between site and disturbance also significantly affected palatable plant biomass. When data from five sites or an individual site were analyzed, the palatable plant biomass was lower in the disturbed plot than in the undisturbed plot (Figure. 1A; Figure. 1B).

\subsubsection{Effect of plateau pika disturbance on plant species richness}

Site and disturbance had significant effects on plant species richness (Table 1), whereas their interaction had no significant effect on plant species richness. On the overall scale or on the individual site scale, the plant species richness in the disturbed plot was higher than that in the undisturbed plot (Figure. 2A; Figure. 2B).

\subsubsection{Effect of plateau pika disturbance on soil water storage}

Site and disturbance were found to have significant effects on soil water storage (Table 1), whereas their interaction was not found to have a significant effect on soil water storage. In contrast to the undisturbed plot, the soil water storage was lower in the disturbed plot when five sites or one site were considered (Figure. 3A; Figure. 3B). 


\subsubsection{Effect of plateau pika disturbance on the soil organic carbon stock}

The soil organic carbon stock was significantly affected by site, disturbance and their interactions (Table 1). When all the sites or the individual site were considered, the soil organic carbon stock in the disturbed plot was higher than that in the undisturbed plot (Figure. 4A; Figure. 4B).

3.1.5 Effects of plateau pika disturbance on the soil total nitrogen, phosphorus and potassium stocks

The soil total nitrogen and total phosphorus stocks were significantly affected by site and disturbance, whereas they were not affected by the interactions between site and disturbance. The soil total potassium stock was found to be affected only by the site (Table 1).

Accounting for an overall scale effect, the soil total nitrogen and the total phosphorus stocks in the disturbed plot were higher than those in the undisturbed plot (Figure. 5A; Figure. 5C), whereas the soil total potassium stock was not different between the disturbed and undisturbed plots (Figure. 5E). Accounting for a site-scale effect, plateau pika disturbance increased the soil total nitrogen stock at Gangcha, Haiyan and Qilian (Figure. 5B) and the soil total phosphorus stock at Luqu and Gonghe (Figure. 5D), whereas it had no impact on the soil total nitrogen stock at Luqu and Gonghe or the soil total phosphorus stock at Gangcha, Haiyan and Qilian; plateau pika disturbance had a similar effect on the soil total potassium stock at each site (Figure. $5 \mathrm{~F})$.

3.2 Effects of plateau pika disturbance intensity on the ecosystem services of alpine grasslands

\subsubsection{Effect of plateau pika disturbance intensity on palatable plant biomass}

The simulation result of the linear model (LM) indicated that the palatable plant biomass showed a significant downward parabola as the disturbance intensity increased when data from five sites (Figure. 6A) or data from individual site (Figure. 6B) were considered.

\subsubsection{Effect of plateau pika disturbance intensity on plant species richness}

Accounting for the five-site scale effect, the plant species richness increased and then decreased as the plateau pika disturbance intensity increased (Figure. 7A). Accounting for one site effect, the plant species richness showed hump-shaped trends at Gangcha, Haiyan and Qilian and increased linearly at Luqu and Gonghe with increasing disturbance intensity (Figure. 7B).

\subsubsection{Effect of plateau pika disturbance intensity on soil water storage}

When five sites were considered, the soil water storage decreased linearly as the plateau pika disturbance intensity increased (Figure. 8A). When individual site was considered, the soil water storage showed downward parabolas at Luqu, Haiyan and Qilian and showed a linearly decreasing curve at Gangcha and Gonghe with increasing disturbance intensity (Figure. 8B).

\subsubsection{Effect of plateau pika disturbance intensity on soil organic carbon stock}

Accounting for an overall scale effect, the soil organic carbon stock showed a significant unimodal curvilinearity as the disturbance intensity increased (Figure. 9A). Considering site-scale effects, the soil organic carbon stock also showed significant unimodal curvilinearity at each site with increasing disturbance intensity (Figure. 9B).

\subsubsection{Effects of plateau pika disturbance intensity on soil total nitrogen, phosphorus andpo-} tassium stocks

When data from the five sites were analyzed together, the soil total nitrogen (Figure 10A), phosphorus (Figure. 11A) and potassium (Figure. 12A) stocks increased and then decreased as the disturbance intensity increased. 
When data from each site were analyzed separately, the relationship between the disturbance intensity and soil total nitrogen (Figure. 10B) and phosphorus (Figure. 11B) stocks was similar at each site, in agreement with the overall scale effect, whereas the relationship between the disturbance intensity and soil total potassium stock was different among five sites, in which the response of soil total potassium stock to the disturbance intensity was similar to the overall scale effect at Luqu and Gonghe (Figure. 12B), whereas it showed no obvious trends at Gangcha, Haiyan and Qilian as the disturbance intensity increased.

\section{DISCUSSION}

This study shows that plateau pika disturbance is related to lower palatable plant biomass and higher plant species richness across five sites or at an individual site, demonstrating that plateau pika disturbance decreases the forage availability service and increases the biodiversity conservation service, in agreement with the first hypothesis. Plateau pika disturbance in relation to lower palatable plant biomass has also been reported in a previous study (Liu et al., 2017), while prairie dog disturbance has been reported to be related to higher palatable plant biomass (Martínez-Estévez et al., 2013). Prairie dog disturbance encourages the arid grassland in North America to shift from annual plants to perennial plants, in which blue gramma (Bouteluoa gracilis ) and vine mesquite (Panicum obtusum ) are usually perennial plants that are palatable for livestock (Sierra-Corona et al., 2015), whereas plateau pika disturbance enables alpine grassland composition to change from sedge to unpalatable broad-leaved plants in the Qinghai-Tibetan Plateau (Pang \& Guo, 2018). In this case, plateau pikas preferentially consume dicotyledons, and most dicotyledons are unpalatable plants (Pang \& Guo, 2017; Zhao et al., 2013). Thus, plateau pika consumption can benefit palatable plant growth (Pang \& Guo, 2017) since it can alleviate the competitive pressure of monocotyledons, and these monocotyledons are palatable plants ( $\mathrm{Li}$ et al., 2015; Zhao et al., 2013). However, plateau pikas often bury many plants in the process of producing bare soil patches, thereby reducing aboveground plants at the plot scale. The decrease in palatable plant biomass, which is derived from bare soil patches and sedge replacement by unpalatable broad-leaved plants, is greater than the increase in palatable plant biomass derived from the alleviation effect of plateau pika consumption. Therefore, plateau pika disturbance contributes to a negative effect on palatable plant biomass, resulting in a decrease in forage availability services. In addition, plateau pika disturbance in relation to higher plant species richness is similar to that of other small burrowing herbivore disturbances, such as that of the plains pocket gopher (Rogers et al., 2001), the coexisting kangaroo rat and mole rat (Davidson \& Lightfoot, 2008), and the prairie dog (Hagenah \& Bennett, 2013). Higher plant species richness caused by plateau pikas can be explained by several mechanisms: first, plateau pika activities are likely to enhance the environmental heterogeneity (Guo et al., 2012b; Pang et al., 2020a; Yu et al., 2017a), which creates gaps for opportunistic plant species (Hagenah \& Bennett, 2013; Pang \& Guo, 2017); second, bare soil patches caused by plateau pikas provide additional good habitat for plant seeds to germinate and settle (Pang \& Guo, 2017) because it is difficult for plant seedlings to survive on vegetated surfaces with 7 to 8 cm root mats with less soil and water supplies (Li et al., 2015); third, the burrow of plateau pikas is the only habitat home for snow finch (Montifringilla ruficollis ) (Liu et al., 2013), and this bird can recruit more plant seeds in areas with plateau pikas. These three processes encourage plateau pika disturbance to increase the biodiversity conservation service.

Plateau pika disturbance is associated with lower soil water storage across all five sites or at each individual site, in contrast to the second hypothesis. This result has also been found in a previous study (Liu et al., 2013), whereas it is different from prairie dog disturbance (Martínez-Estévez et al., 2013). The different responses of soil water storage to disturbance by small burrowing herbivores are ascribed to the soil porosity and compaction of grassland. Prairie dog disturbance increases soil water storage by reducing the compaction and increasing the pore spaces of arid grassland (Martínez-Estévez et al., 2013), while plateau pika disturbance has no impact on the soil bulk density of alpine grassland (Pang et al., 2020b) and encourages more topsoil water to infiltrate into deep soil though bare soil patches and burrow entrances in root mats (Li et al., 2015), contributing to a decrease in soil water storage in the topsoil layer. In addition, bare soil patches caused by plateau pikas can increase water evaporation in topsoil because of the lack of vegetation insulation. Thus, the plateau pika disturbance results in low soil water storage in the topsoil layer, contributing to a reduction in the water conservation service. 
Plateau pika disturbance correlates with higher soil organic carbon stock and does not relate to soil total potassium stock across the five sites or individual site, whereas plateau pika disturbance has different impacts on soil total nitrogen stock and soil total phosphorus stock among five sites, demonstrating that there is a general pattern for plateau pika disturbance in relation to carbon sequestration and soil potassium maintenance services, and no general pattern concerns the effects of plateau pika disturbance on the soil total nitrogen and total phosphorus maintenance services. These results support the third hypothesis but do not support the fourth hypothesis. In this case, plateau pika disturbance can increase the soil organic carbon stock in two possible ways: first, plateau pika disturbance can input extra organic matter through the deposition of uneaten food (Liu et al., 2009; Liu et al., 2013; Yu, et al., 2017a; Zhang et al., 2016) and the excretion of urine and feces (James et al., 2009; Yu et al., 2017b); second, the burrowing behavior of plateau pikas can protect the soil organic matter pools from ultraviolet light and cannot be blown away by wind (Pang et al., 2020a), which reduces the decomposition, mineralization and removal of soil organic matter (Clark et al., 2016; Yurkewycz et al., 2014). Since the responses of soil total nitrogen and total phosphorus maintenance to plateau pika disturbance are site-dependent, which is similar to previous studies (Pang et al. 2020b), soil total nitrogen and phosphorus maintenance is not suitable for estimating the effect of disturbance by small burrowing herbivores on the ecosystem services of alpine grasslands.

Additionally, this study found that plateau pika disturbance intensity was also related to palatable plant biomass, plant species richness, soil water storage, soil organic carbon stock, and soil total nitrogen and phosphorus stocks. As the disturbance intensity increases, the palatable plant biomass, plant species richness, soil organic carbon stock, soil total nitrogen and phosphorus stocks show downward parabolas, demonstrating that there is a threshold of plateau pika disturbance intensity for maximizing the forage availability, biodiversity conservation, carbon sequestration, and soil nitrogen and phosphorus maintenance services. When the disturbance intensity is within the threshold of disturbance intensity, plateau pika disturbance can enhance soil total nitrogen (Li et al., 2014) and organic carbon accumulation (Yu et al., 2017b), increase palatable plant biomass (Pang \& Guo, 2018) by improving the growth potential of grass plants (Wang et al., 2012b), and encourage more hygrophytes and mesophytes, annual and perennial, common and rare plants to coexist (Guo et al., 2012b), contributing to higher forage available, biodiversity conservation, carbon sequestration, soil total nitrogen and phosphorus maintenance services. When the disturbance intensity is below the threshold of disturbance intensity, the dominant sedge plants place great competitive pressure on grass plants, which leads grass plants to maintain a low percentage (Pang \& Guo, 2018; Wang et al., 2012b) and makes it difficult for rare plants to coexist. Once the disturbance intensity surpasses its threshold, low soil water content in alpine grassland (Liu et al., 2013) only sustains the xerophytes and mesophytes, most of which are unpalatable (Pang \& Guo, 2018), resulting in reductions in palatable plant biomass and plant species richness. Notably, the responses of plant species richness to plateau pika disturbance intensity showed linear increases at Luqu and Gonghe, which were ascribed to the disturbance intensity. The disturbance intensities at these two sites were lower than the threshold of disturbance intensity (Table 2), which validates the general patterns of plateau pika disturbance intensity in relation to plant species richness. Plateau pika disturbance can increase the input of soil organic matter (Pang \& Guo, 2017; Pang et al., 2020a), and this increase in soil organic matter is lower when the disturbance intensity is below the threshold. Low vegetation biomass at high disturbance intensities (Pang \& Guo, 2017; Pang et al., 2020a; Sun et al., 2015) also decreases the input of soil organic matter. Thus, soil organic carbon sequestration and soil nitrogen and phosphorus maintenance services are low when the disturbance intensity is below or over the thresholds.

In contrast to forage availability, biodiversity conservation, carbon sequestration, soil nitrogen and phosphorus maintenance services, the water conservation service shows a decreasing trend as the plateau pika disturbance intensity increases, which is ascribed to evaporation and water infiltration on bare soil patches. Previous studies have shown that evaporation and water infiltration from topsoil to deep soil are higher in bare soil patches than in vegetated surfaces (Liu et al., 2013; Yu et al., 2017b). As the soil bare area increases, the amount of water evaporation and infiltration shows an increasing trend (Liu et al., 2013), which encourages the soil water storage to decrease, contributing to a gradual decrease in the water conservation services of alpine grasslands. 
Data from one site show that prairie dog disturbance has a positive impact on grassland ecosystem services in arid regions of North America (Martínez-Estévez et al., 2013), whereas data from five sites show that plateau pika disturbance and its disturbance intensity have a positive or negative impact on different ecosystem services of alpine grasslands in the Qinghai-Tibetan Plateau. Thus, a general pattern can be identified for the effect of plateau pika disturbance on forage availability, biodiversity conservation, water conservation and carbon sequestration services, whereas the soil nutrient maintenance service in relation to plateau pika disturbance varies by site. These results indicated that plateau pika control should consider the management target of ecosystem services for alpine grasslands and its disturbance intensity threshold in the QinghaiTibetan Plateau. The findings of this study present a possible pattern of how disturbance by small burrowing herbivores influences grassland ecosystem services and open a broader vision for insight into small burrowing herbivore in relation to grassland ecosystem services.

\section{REFERENCES}

Clark, K.L., Branch, L.C., Hierro, J.L., \& Villarreal, D. (2016). Burrowing herbivores alter soil carbon and nitrogen dynamics in a semi-arid ecosystem, Argentina. Soil Biology and Biochemistry 103 , 253261.https://doi.org/10.1016/j.soilbio.2016.08.027

Costanza, R., D’Arge, R., De Groot, R., Farber, S., Grasso, M., Hannon, B., Limburg, K., Naeem, S., O’Neill, R., Paruelo, J., Raskin, R.G., Sutton, P., \& Van Den Belt, M. (1997). The value of the world's ecosystem services and natural capital. Nature ,387(6630) , 253-260.https://doi.org/10.1038/387253a0

Davidson, A.D., \& Lightfoot, D.C. (2008). Burrowing rodents increase landscape heterogeneity in a desert grassland. Journal of Arid Environments 72(7) , 1133-1145.

Davidson, A.D., Detling, J.K., \& Brown, J.H. (2012). Ecological roles and conservation challenges of social, burrowing, herbivorous mammals in the world's grasslands. Frontiers in Ecology and the Environment 10(9), 477-486.https://doi.org/10.1890/110054

Dong, S.K., Wen, L., Zhu, L., \& Li, X.Y. (2010). Implication of coupled natural and human systems in sustainable rangeland ecosystem management in HKH region. Frontiers of Earth Science in China 4(1), 42-50.https://doi.org/10.1007/s11707-010-0010-z

Dong, S.K., Shang, Z.H., Gao, J.X., \& Boone, R.B. (2020). Enhancing sustainability of grassland ecosystems through ecological restoration and grazing management in an era of climate change on Qinghai-Tibetan Plateau. Agriculture, Ecosystems 83 Environment 287.

Fan, N., Zhou, W., Wei, W., Wang, Q., \& Jiang, Y. (1999). Rodent pest management in the Qinghai-Tibet alpine meadow ecosystem. In: Singleton, G. R., Hinds, L. A., Leirs, H., Zhang, Z. (eds.). Ecologically-based rodent management. Australian Centre for International Agricultural Research, Canberra, Australia, pp 285-304.

Gong, Z., 2001. Chinese Soil Taxonomy. Science Press, China (in Chinese).

Guo, Z.G., Zhou, X.R., \& Hou, Y. (2012a). Effect of available burrow densities of plateau pika (Ochotona curzoniae ) on soil physicochemical property of the bare land and vegetation land in the Qinghai-Tibetan Plateau. Acta Ecologica Sinica 32(2), 104-110.

Guo, Z.G., Li, X.F., Liu, X.Y., \& Zhou, X.R. (2012b). Response of alpine meadow communities to burrow density changes of plateau pika (Ochotona curzoniae) in the Qinghai-Tibet Plateau. Acta Ecologica Sinica 32(1), 44-49.https://doi.org/10.1016/j.chnaes.2011.12.002

Han, L.H., Shang, Z.H., Ren, G.H., Wang, Y.L., Ma, Y.S., Li, X.L., \& Long, R.J. (2011). The response of plants and soil on black soil patch of the Qinghai-Tibetan Plateau to variation of bare-patch areas.Acta Prataculturae Sinica, 20(1) , 1-6. DOI:1004-5759(2011)01-001-06

Hagenah, N., \& Bennett, N.C. (2013). Mole rats act as ecosystem engineers within a biodiversity hotspot, the Cape Fynbos. Journal of Zoology, 289(1) , 19-26. http://dx.doi.org/10.11 11/j.14 69-7998.2012.00958.x 
James, A.I., Eldridge, D.J., \& Hill, B.M. (2009). Foraging animals create fertile patches in an Australian desert shrubland.Ecography 32(5) , 723-732.https://doi.org/10.1111/j.1600-0587.2009.05450.x

Jäger, H., Peratoner, G., Tappeiner, U., \& Tasser, E. (2020). Grassland biomass balance in the European Alps: current and future ecosystem service perspectives. Ecosystem Services, 45(July), 101163.https://doi.org/10.1016/j.ecoser.2020.101163

Jia, Q.M., Xu, R.R., Chang, S.H., Zhang, C., Liu, Y.J., Shi, W., Peng, Z.C., \& Hou, F.J. (2020). Planting practices with nutrient strategies to improves productivity of rain-fed corn and resource use efficiency in semi-arid regions. Agricultural Water Management 228 .

Li, Q.Q., Zhao, X., \& Guo, Z.G. (2014). Effect of available burrow densities of plateau pika (Ochotona curzoniae ) on leaf nitrogen and phosphorus stoichiometry of dominant plants and soil in alpine meadow. Acta Ecologica Sinica, 34(5) ,1212-1223. DOI: 10.5846/stxb20 1305070975

Li, J., Zhang, F.W., Lin, L., Li, H.Q., Du, Y.G., Li, Y.K., \& Cao, G.M. (2015). Response of the plant community and soil water status to alpine Kobresia meadow degradation gradients on the Qinghai-Tibetan Plateau, China. Ecological Research 30(4), 589-596.

Liu, W., Zhang, Y., Wang, X., Zhao, J.Z., Xu, Q.M., \& Zhou, L. (2009). The relationship of the harvesting behavior of plateau pikas with the plant community. Acta Theriologica Sinica 29(1) , 4049.http://doi.org/10.16829/j.slxb.2009.01.007

Liu, Y.S., Fan, J.W., Harris, W., Shao, Q.Q., Zhou, Y.C., Wang, N., \& Li, Y.Z. (2013). Effects of plateau pika (Ochotona curzoniae ) on net ecosystem carbon exchange of grassland in the Three Rivers Headwaters region, Qinghai-Tibet, China. Plant and Soil 366(1-2) , 491-504.https://doi.org/10.1007/s11104-012-1442-x

Lu, X.Y., Kelsey, K.C., Yan, Y., Sun, J., Wang, X.D., Cheng, G.W., \& Neff, J.C. (2017). Effects of grazing on ecosystem structure and function of alpine grasslands in Qinghai-Tibetan Plateau: A synthesis.Ecosphere, 8(1) .https://doi.org/10.1002/ecs2.1656

Liu, Y.S., Fan, J.W., Shi, Z.J., Yang, X.H., \& Harris, W. (2017). Relationships between plateau pika (Ochotona curzoniae ) densities and biomass and biodiversity indices of alpine meadow steppe on the Qinghai-Tibet Plateau China. Ecological Engineering 102, 509-518.https://doi.org/10.1016/j.ecoleng.2017.02.026

Martínez-Estévez, L., Balvanera, P., Pacheco, J., \& Ceballos, G. (2013). Prairie dog decline reduces the supply of ecosystem services and leads to desertification of semiarid grasslands. PLoS One 8(10), e75229.https://doi.org/10.1371/journal.pone.0075229

McGranahan, D.A., Engle, D.M., Fuhlendorf, S.D., Winter, S.J., Miller, J.R., \& Debinski, D.M. (2012). Spatial heterogeneity across five rangelands managed with pyric-herbivory. Journal of Applied Ecology 49(4) , 903-910.https://doi.org/10.1111/j.1365-2664.2012.02 168.x

Nelson, D.W., \& Sommers, L.E. (1982). Total carbon, organic carbon, and organic matter. Methods of soil analysis. In: Part 3-Chemical and Microbiological Properties, pp. 539-579

Niu, K.C., Zhang, S.T., Zhao, B.B., \& Du, G.Z. (2010). Linking grazing response of species abundance to functional traits in the Tibetan alpine meadow. Plant and Soil 330(1-2) , 215223.https://doi.org/10.1007/s11104-009-0194-8

Obermeier, W.A., Lehnert, L.W., Pohl, M.J., Makowski Gianonni, S., Silva, B., Seibert, R., Laser, H., Moser, G., Müller, C., Luterbacher, J., \& Bendix, J. (2019). Grassland ecosystem services in a changing environment: The potential of hyperspectral monitoring. Remote Sensing of Environment 232 .

https://doi.org/10.1016/j.rse.2019.111273

Ouyang, Z.Y., Jin, Y., Zhao, T.Q., \& Zheng, H. (2011). Ecosystem Regulating Services and their Valuation of Hainan Island, China.Journal of Resources and Ecology 2(2) , 132-140.DOI: 10.3969/j.issn.1674764x.2011.02.005 
Pang, X.P., \& Guo, Z.G. (2017). Plateau pika disturbances alter plant productivity and soil nutrients in alpine meadows of the Qinghai-Tibetan Plateau, China. Rangeland Journal , 39(2) , 133144.https://doi.org/10.1071/RJ16093

Pang, X.P., \& Guo, Z.G. 2018. Effects of plateau pika disturbance levels on the plant diversity and biomass of an alpine meadow.Grassland Science 64(3) , 159-166.https://doi.org/10.11 11/grs.12199

Pang, X.P., Wang, Q., Zhang, J., Xu, H.P., Zhang, W.N., Wang, J., \& Guo, Z.G. (2020a). Responses of soil inorganic and organic carbon stocks of alpine meadows to the disturbance by plateau pikas. European Journal of Soil Science 71(4), 706-715.https://doi.org/10.1111/e jss.12895

Pang, X.P., Yu, C.Q., Zhang, J., Wang, Q., Guo, Z.G., \& Tian, Y. (2020b). Effect of disturbance by plateau pika on soil nitrogen stocks in alpine meadows. Geoderma 372 : 114392

Qu, J.P., Li, W.J., Yang, M., Ji, W.H., \& Zhang, Y.M. (2013). Life history of the plateau pika (Ochotona curzoniae) in alpine meadows of the Tibetan Plateau. Mammalian Biology 78(1), 6872.https://doi.org/10.1016/j.mambio.2012.09.005

Rogers, W.E., Hartnett, D.C., \& Elder, B. (2001). Effects of Plains Pocket Gopher (Geomys bursarius ) Disturbances on Tallgrass-prairie Plant Community Structure. The American Midland Naturalist 145(2), 344-357.https://doi.org/10.1674/0003-0031(2001)145[034 4:E OPPGG]2.0.CO;2

Sierra-Corona, R., Davidson, A., Fredrickson, E.L., Luna-Soria, H., Suzan-Azpiri, H., Ponce-Guevara, E., \& Ceballos, G. (2015). Black-tailed prairie dogs, cattle, and the conservation of North America's Arid Grasslands. PLoS ONE , 10(3) .https://doi.org/10.1371/journal.p one. 0118602

Smith, A.T., \& Foggin, J.M. (1999). The plateau pika (Ochotona curzoniae) is a keystone species for biodiversity on the Tibetan plateau. Animal Conservation, 2(4) , 235-240.

Smith, A.T., Wilson, M.C., \& Hogan, B.W. (2019). Functional-trait ecology of the plateau pika Ochotona curzoniae in the Qinghai-Tibetan Plateau ecosystem. Integrative Zoology, 14(1) , 87103.http://dx.doi.org/10.1111/1749-4877.12300

Sun, D.S., Wesche, K., Chen, D.D., Zhang, S.H., Wu, G.L., Du, G.Z., \& Comerford, N.B. (2011). Grazing depresses soil carbon storage through changing plant biomass and composition in a Tibetan alpine meadow.Plant, Soil and Environment, 57(6) ,271-278.https://doi.org/1 0.17221/7/2011-pse

Sun, F.D., Chen, W.Y., Liu, L., Liu, W., Cai, Y.M., \& Smith, P. (2015). Effects of plateau pika activities on seasonal plant biomass and soil properties in the alpine meadow ecosystems of the Tibetan Plateau. Grassland Science 61(4), 195-203.https://doi.org/10.1111/grs.1 2101

Wang, X.D., Yan, Y., \& Cao, Y.Z. (2012a). Impact of historic grazing on steppe soils on the northern Tibetan Plateau. Plant and Soil 354(1-2), 173-183.http://dx.doi.org/10.10 07/s11104-011-1053-y

Wang, C.T., Wang, G.X., Liu, W., Wang, Q.L., \& Xiang, Z.Y. (2012b). Vegetation roots and soil physical and chemical characteristics in degeneration succession of the Kobresia pygmaea meadow. Ecol Environ 21, 409-416. DOI: 10.16258/j.cnki.1674-5906.2012.03.002

Wang, Q., Guo, Z.G., Pang, X.P., Zhang, J., \& Yang, H. (2020). Effects of small-herbivore disturbance on the clonal growth of two perennial graminoids in alpine meadows. Alpine Botany 130 , 115127.https://doi.org/10.1007/s00035-020-00240-9

Wen, L., Dong, S.K., Li, Y.Y., Li, X.Y., Shi, J.J., Wang, Y.L., Liu, D.M., \& Ma, Y.S. (2013). Effect of degradation intensity on grassland ecosystem services in the alpine region of Qinghai-Tibetan Plateau, China. PLoS One 8(3), e58432.https://doi.org/10.1371/journ al.pone.00 58432

Wilson, M.C., \& Smith, A.T. (2015). The pika and the watershed: The impact of small mammal poisoning on the ecohydrology of the Qinghai-Tibetan Plateau. Ambio, 44(1), 16-22.https://doi.org/10.1007/s13280$014-0568-x$ 
Woldu, Z., \& Saleem, M.A.M. (2000). Grazing induced biodiversity in the highland ecozone of East Africa. Agriculture, Ecosystems and Environment, 79(1), 43-52.

Wu, G.L., Du, G.Z., Liu, Z.H., \& Thirgood, S. (2009). Effect of fencing and grazing on a Kobresia-dominated meadow in the Qinghai-Tibetan Plateau. Plant and Soil, 319(1-2) , 115-126.https://doi.org/10.1007/s11104008-9854-3

Yu, C., Pang, X.P., Wang, Q., Jin, S.H., Shu, C.C., \& Guo, Z.G. (2017a). Soil nutrient changes induced by the presence and intensity of plateau pika (Ochotona curzoniae) disturbances in the Qinghai-Tibet Plateau, China. Ecological Engineering $106,1-9$. ttps://doi.org/1 0.1016/j.ecoleng.2017.05.029

Yu, C., Zhang, J., Pang, X.P., Wang, Q., Zhou, Y.P., \& Guo, Z.G. (2017b). Soil disturbance and disturbance intensity: Response of soil nutrient concentrations of alpine meadow to plateau pika bioturbation in the Qinghai-Tibetan Plateau, China. Geoderma 307, 98-106.https://doi.org/10.1016/j.geoderma.2017.07.041

Yurkewycz, R.P., Bishop, J.G., Crisafulli, C.M., Harrison, J.A., \& Gill, R.A. (2014). Gopher mounds decrease nutrient cycling rates and increase adjacent vegetation in volcanic primary succession. Oecologia 176(4) , 1135-1150.https://doi.org/10.1007/s00442-014-3075-7

Zhang, T., Zhang, Y.J., Xu, M.J., Zhu, J.T., Wimberly, M.C., Yu, G.R., Niu, S.L., Xi, Y., Zhang, X.Z., \& Wang, J.S. (2015). Light-intensity grazing improves alpine meadow productivity and adaption to climate change on the Tibetan Plateau. Sci Rep 5 , 15949.https://doi.org/10.1038/srep15949

Zhang, Y., Dong, S.K., Gao, Q.Z., Liu, S.L., Liang, Y., \& Cao, X.J. (2016). Responses of alpine vegetation and soils to the disturbance of plateau pika (Ochotona curzoniae) at burrow level on the Qinghai-Tibetan Plateau of China. Ecological Engineering 88, 232-236.https://doi.org/10.1016/j.ecoleng.2015.12.034

Zhang, H.Y., Fan, J.W., Cao, W., Zhong, H.P., Harris, W., Gong, G.L., \& Zhang, Y.X. (2018). Changes in multiple ecosystem services between 2000 and 2013 and their driving factors in the Grazing Withdrawal Program, China. Ecological Engineering 116, 67-79.

Zhang, W.N., Wang, Q., Zhang, J., Pang, X.P., Xu, H.P., Wang, J., \& Guo, Z.G. (2020). Clipping by Plateau Pikas and Impacts to Plant Community. Rangeland Ecology 83 Management 73(3) , 368374.https://doi.org/10.1016/j.rama.2020.01.010

Zhao, G.Q., Li, G.Y., Ma, W.H., Zhao, D.Z., \& Li, X.Y. (2013). Impacts of Ochotona pallasi disturbance on alpine grassland community characteristics. Chinese Journal of Applied Ecology 24,21222128.http://doi.org/10.13287/j.1001-9332.2013.0398

Zhao, J.X., Tian, L.H., Wei, H.X., Zhang, T., Bai, Y.F., Li, R.C., \& Tang, Y.H. (2019). Impact of plateau pika (Ochotona curzoniae) burrowing-induced microtopography on ecosystem respiration of the alpine meadow and steppe on the Tibetan plateau. Plant and Soil .2019:1-14

\section{Table legends}

Table 1 Palatable plant biomass, plant species richness, soil water storage, soil organic carbon stock, soil total nitrogen stock, soil total phosphorus stock and soil total potassium stock in relation to plateau pika disturbance (disturbance), site (site) and their interaction.

Table 2 Percentage of bare soil area of the total plot area $(35 \mathrm{~m}$ ? $35 \mathrm{~m})$ in the presence of plateau pikas. Significance was evaluated using one-way ANOVA with the Tukey post hoc test. Different letters denote significant differences at $P<0.05$. Presented are the means +-1 standard deviation for the five sites; each site had 10 replicates $(\mathrm{n}=50)$.

\section{Table 1}

\begin{tabular}{lllllllll}
\hline Response variable & Site & Site & Disturbance & Disturbance & Disturbance & Disturbance & Disturbance & S \\
\hline & F & $P$ & $P$ & F & $P$ & & F
\end{tabular}




\begin{tabular}{|c|c|c|c|c|c|c|c|}
\hline Response variable & Site & Site & Disturbance & Disturbance & Disturbance & Disturbance & Disturbance \\
\hline Palatable plant biomass & 5.857 & 0.058 & 0.058 & & 17.331 & 0.014 & \\
\hline Plant species richness & 59.074 & 0.001 & 0.001 & & 28.058 & 0.006 & \\
\hline Soil water storage & 111.215 & 0.000 & 0.000 & & 76.053 & 0.001 & \\
\hline Soil organic carbon stock & 12.544 & 0.016 & 0.016 & & 21.033 & 0.010 & \\
\hline Soil total nitrogen stock & 46.779 & 0.001 & 0.001 & & 90.628 & 0.001 & \\
\hline Soil total phosphorus stock & 6.557 & 0.048 & 0.048 & & 11.204 & 0.029 & \\
\hline Soil total potassium stock & 10.317 & 0.022 & 0.022 & & 0.004 & 0.955 & \\
\hline
\end{tabular}

Table 2

\begin{tabular}{ll}
\hline Location & Bare soil area $(\%)$ \\
\hline Luqu & $6.67 \pm 1.00 \mathrm{~b}$ \\
Gangcha & $12.82 \pm 1.58 \mathrm{a}$ \\
Haiyan & $12.80 \pm 2.34 \mathrm{a}$ \\
Qilian & $11.56 \pm 1.89 \mathrm{a}$ \\
Gonghe & $6.48 \pm 1.04 \mathrm{~b}$ \\
\hline
\end{tabular}

\section{Figure legends}

FIGURE 1 Palatable plant biomass of undisturbed and disturbed plots across five sites (A) and each site (B) (mean \pm standard error).

FIGURE 2 Plant species richness of the undisturbed and disturbed plots across five sites (A) and each site (B) (mean \pm standard error).

FIGURE 3 Soil water storage of the undisturbed and disturbed plots across five sites (A) and each site (B) (mean \pm standard error)

FIGURE 4 Soil organic carbon stock of undisturbed and disturbed plots across five sites (A) and each site (B) (mean \pm standard error).

FIGURE 5 Soil total nitrogen stock of undisturbed and disturbed plots across five sites (A) and each site (B) (mean \pm standard error), soil total phosphorus stock of undisturbed and disturbed plots across five sites (C) and each site (D) (mean \pm standard error), soil total potassium stock of undisturbed and disturbed plots across five sites (E) and each site (F) (mean \pm standard error).

FIGURE 6 Relationship between palatable plant biomass and plateau pika disturbance intensity across five sites (A) and each site (B) based on linear models (LMs). An adjusted local smoothed regression line (A) and five adjusted local smoothed regression lines (B) were used to determine the relationship between the disturbance intensity and each palatable plant biomass with data from five sites and individual site data, respectively.

FIGURE 7 Relationship between plant species richness and plateau pika disturbance intensity across five sites (A) and each site (B) based on linear models (LMs).

FIGURE 8 Relationship between soil water storage and plateau pika disturbance intensity across five sites (A) and each site (B) based on linear models (LMs).

FIGURE 9 Relationship between soil organic carbon stock and plateau pika disturbance intensity across five sites (A) and each site (B) based on linear models (LMs).

FIGURE 10 Relationship between soil total nitrogen stock and plateau pika disturbance intensity across five sites (A) and each site (B) based on linear models (LMs). 
FIGURE 11 Relationship between soil total phosphorus stock and plateau pika disturbance intensity across five sites (A) and each site (B) based on linear models (LMs).

FIGURE 12 Relationship between soil total potassium stock and plateau pika disturbance intensity across five sites (A) and each site (B) based on linear models (LMs).

\section{Hosted file}

image1.emf available at https://authorea.com/users/389176/articles/503789-effect-of-plateaupika-disturbance-on-the-ecosystem-services-of-alpine-grasslands

FIGURE 1 Palatable plant biomass of undisturbed and disturbed plots across five sites (A) and each site (B) (mean \pm standard error).

\section{Hosted file}

image2.emf available at https://authorea.com/users/389176/articles/503789-effect-of-plateaupika-disturbance-on-the-ecosystem-services-of-alpine-grasslands

FIGURE 2 Plant species richness of the undisturbed and disturbed plots across five sites (A) and each site (B) (mean \pm standard error).

\section{Hosted file}

image3.emf available at https://authorea.com/users/389176/articles/503789-effect-of-plateaupika-disturbance-on-the-ecosystem-services-of-alpine-grasslands

FIGURE 3 Soil water storage of the undisturbed and disturbed plots across five sites (A) and each site (B) (mean \pm standard error).

\section{Hosted file}

image4.emf available at https://authorea.com/users/389176/articles/503789-effect-of-plateaupika-disturbance-on-the-ecosystem-services-of-alpine-grasslands

FIGURE 4 Soil organic carbon stock of undisturbed and disturbed plots across five sites (A) and each site (B) (mean \pm standard error).

\section{Hosted file}

image5.emf available at https://authorea.com/users/389176/articles/503789-effect-of-plateaupika-disturbance-on-the-ecosystem-services-of-alpine-grasslands

FIGURE 5 Soil total nitrogen stock of undisturbed and disturbed plots across five sites (A) and each site (B) (mean \pm standard error), soil total phosphorus stock of undisturbed and disturbed plots across five sites (C) and each site (D) (mean \pm standard error), soil total potassium stock of undisturbed and disturbed plots across five sites (E) and each site (F) (mean \pm standard error).

\section{Hosted file}

image6.emf available at https://authorea.com/users/389176/articles/503789-effect-of-plateaupika-disturbance-on-the-ecosystem-services-of-alpine-grasslands

FIGURE 6 Relationship between palatable plant biomass and plateau pika disturbance intensity across five sites (A) and each site (B) based on linear models (LMs). An adjusted local smoothed regression line (A) and five adjusted local smoothed regression lines (B) were used to determine the relationship between the disturbance intensity and each palatable plant biomass with data from five sites and individual site data, respectively.

\section{Hosted file}


image7.emf available at https://authorea.com/users/389176/articles/503789-effect-of-plateaupika-disturbance-on-the-ecosystem-services-of-alpine-grasslands

FIGURE 7 Relationship between plant species richness and plateau pika disturbance intensity across five sites (A) and each site (B) based on linear models (LMs).

\section{Hosted file}

image8.emf available at https://authorea.com/users/389176/articles/503789-effect-of-plateaupika-disturbance-on-the-ecosystem-services-of-alpine-grasslands

FIGURE 8 Relationship between soil water storage and plateau pika disturbance intensity across five sites (A) and each site (B) based on linear models (LMs).

\section{Hosted file}

image9.emf available at https://authorea.com/users/389176/articles/503789-effect-of-plateaupika-disturbance-on-the-ecosystem-services-of-alpine-grasslands

FIGURE 9 Relationship between soil organic carbon stock and plateau pika disturbance intensity across five sites (A) and each site (B) based on linear models (LMs).

\section{Hosted file}

image10.emf available at https://authorea.com/users/389176/articles/503789-effect-ofplateau-pika-disturbance-on-the-ecosystem-services-of-alpine-grasslands

FIGURE 10 Relationship between soil total nitrogen stock and plateau pika disturbance intensity across five sites (A) and each site (B) based on linear models (LMs).

\section{Hosted file}

image11.emf available at https://authorea.com/users/389176/articles/503789-effect-ofplateau-pika-disturbance-on-the-ecosystem-services-of-alpine-grasslands

FIGURE 11 Relationship between soil total phosphorus stock and plateau pika disturbance intensity across five sites (A) and each site (B) based on linear models (LMs).

\section{Hosted file}

image12.emf available at https://authorea.com/users/389176/articles/503789-effect-ofplateau-pika-disturbance-on-the-ecosystem-services-of-alpine-grasslands

FIGURE 12 Relationship between soil total potassium stock and plateau pika disturbance intensity across five sites (A) and each site (B) based on linear models (LMs). 